L4YMP9808120

's

\title{
Water Entering Waste Packages: Drawdown Limited Flow on the Waste Package Surface
}

\author{
Ernest Hardin
}

This paper was prepared for submittal to the International High-Level Radioactive Waste Management Conference Las Vegas, $N V$

May 11-14, 1998

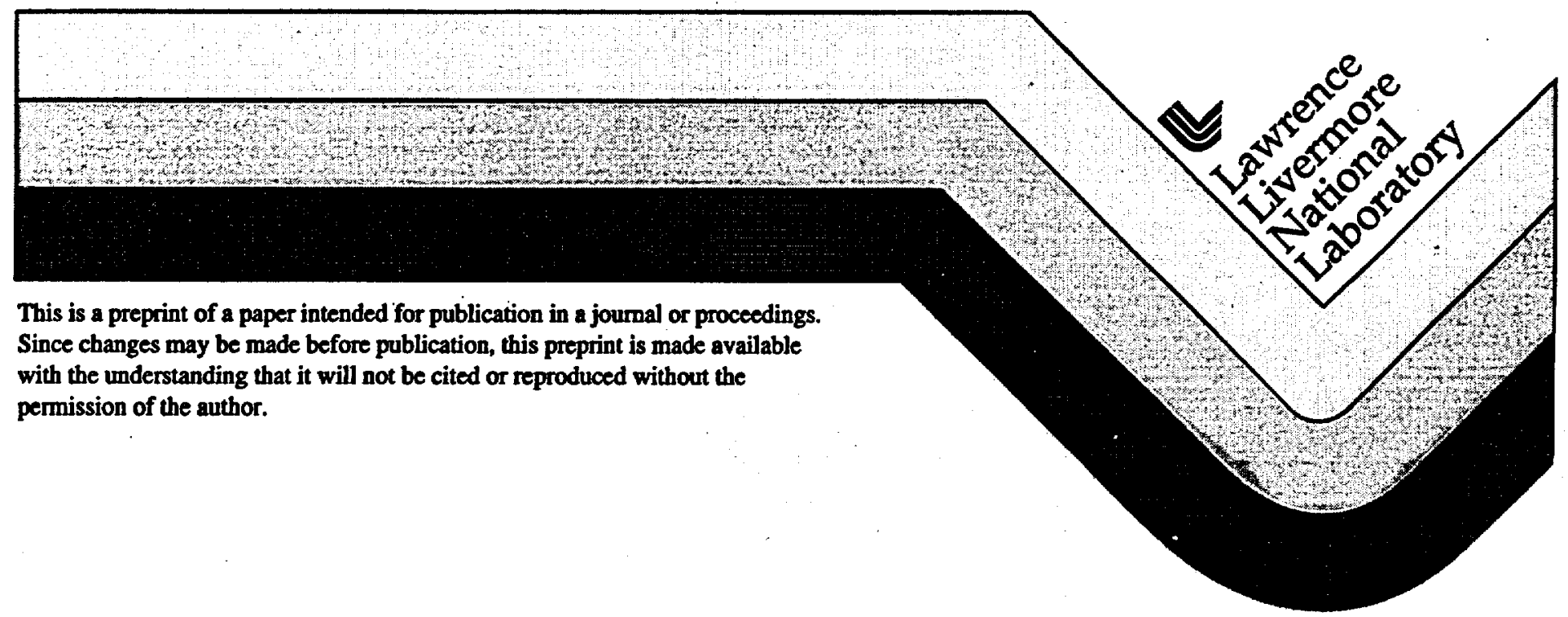




\section{DISCLAMMER}

This document was prepared as an account of work sponsored by an agency of the United States Government. Neither the United States Government nor the University of Califomia nor any of their employees, makes any warranty, express or implied, or assumes any legal liability or responsibility for the accuracy, completeness, or usefulness of any information, apparatus, product, or process disclosed, or represents that its use would not infringe privately owned rights. Reference herein to any specific commercial product, process, or service by trade name, trademark, manufacturer, or otherwise, does not necessarily constitute or imply its endorsement, recommendation, or favoring by the United States Government or the University of Califomia. The views and opinions of authors expressed herein do not necessarily state or reflect those of the United States Government or the University of Califomia, and shall not be used for advertising or product endorsement purposes. 


\title{
Water Entering Waste Packages: Drawdown LImited Flow \\ on the Waste Package Surface
}

\author{
Extended Abstract \\ Ernest Hardin \\ Lawrence Livermore National Laboratory/CRWMS M\&O
}

Approach

This analysis addresses the question: How much of the water that impinges onto the waste packages actually enters, contributing to the advective mode of release? The answers presented here involve two conceptual models for water flow on the outside of a waste package:

- Flow of a water film on the smooth, wetted surface of the waste package (Stokes flow). This model represents a relatively uncorroded waste package surface, on which debris accumulation is limited to a thin layer of small particles.

- Flow in a wetted, uniform porous layer surrounding the waste package (Dupuit flow). This model represents a heavily corroded surface, and/or the waste package surface in contact with backfill.

For a heavily corroded surface which may be buried by heterogeneous debris, the porous layer model approximates the surface with an equivalent hydraulic conductivity that can be varied to study its influence on water entering the waste package.

These analyses are based on the conceptualization of corrosion-caused perforations in corrosion resistant material, as narrow pits which are known to occur in candidate materials. The

perforations are partially plugged with corrosion products and other particles, resulting in a linear hydraulic conductance that can be represented by a Darcy conductivity for the perforation plug.

Each perforation tends to draw water from a surrounding region, and the region tends to become depleted, limiting flow to the perforation. This is referred to in this discussion as drawdown limited flow. The size of the region influenced by drawdown around a perforation is related to the local velocity and thickness of the flow layer on the surface, and the steady state flow rate into the perforation. The size of this region is represented by a capture radius. Depending on the number density of perforations and their spatial distribution, the capture radii may interfere, further limiting flow into the waste package.

\section{Results and Conclusions}

Calculations incorporating drawdown limited flow and interference between perforations, produced the following observations. If the waste package surface remains sufficiently smooth to support predominantly film flow, or porous layer flow with a very thin layer, then the proportion of incident flux that enters the waste package will be limited to approximately $10 \%$ or less. For total system performance calculations using the advective mode of release from the waste package, this is equivalent to at least an order of magnitude improvement in the calculated dose. This type of performance could be achieved by a drip shield constructed from corrosion resistant metal alloy (possibly with a ceramic coating) if the surface of the shield is not covered by debris or backfill.

Water entering the waste package is reduced by about an order of magnitude, for flux on the order of $10 \mathrm{~mm} / \mathrm{yr}$ or greater and perforation number density less than $100 \mathrm{~m}^{-2}$, if the perforation plug conductivity is on the order of $10^{-7} \mathrm{~m} / \mathrm{sec}$ or less. Few empirical data are available for the 
properties of the material that is likely to form plugs within perforations. In addition, this analysis has assumed that the corroded surface of the perforations in the corrosion resistant material will be fully wetted. If it is only partially wetted there will be an additional, capillary barrier to water entry into the waste package for as long as the corrosion resistant material remains a substantially coherent layer and the perforations are narrow pits.

The mechanism of drawdown limited flow can reduce the water entering the waste package by orders of magnitude. However, a thick porous layer on the surface of the waste package causes increased water entry through perforations, unless the perforation plug conductivity is less than or equal to that of the layer $\left(\mathrm{K}_{\mathrm{p}} \leq \mathrm{K}\right)$.

Expanding on the latter point, for incident flux in the range of 1 to $100 \mathrm{~mm} / \mathrm{yr}$, and perforation number density up to $100 \mathrm{~m}^{-2}$, at least one order of magnitude reduction in water entering the waste package is obtained if $K_{p} \approx K$ (Figure 1). Whereas the perforation plug conductivity is difficult to estimate, significant reduction of water entering the waste package is inferred when $\mathrm{K}_{\mathrm{p}} \leq \mathrm{K}$, even for $\mathrm{K}$ as great as $10^{-5} \mathrm{~m} / \mathrm{sec}$ (1 darcy). This should be easier to demonstrate than showing that perforation plug conductivity will be $10^{-7} \mathrm{~m} / \mathrm{sec}$ or less.

Finally, if the waste package is covered by a porous layer of corrosion products or backfill, and if the perforations are relatively permeable $\left(\mathrm{K}_{\mathrm{p}}>\mathrm{K}\right)$, then water entering the waste package could still be strongly limited if the number density of perforations is small $\left(<<100 \mathrm{~m}^{-2}\right.$ ).

This study has used analytical solutions to evaluate water entry into waste packages. The use of an average incident flux is a slight limitation to the applicability of these results. The actual distribution of incident flux on the waste package surface may be heterogeneous, at the scale of individual drips. Moreover, when falling droplets impact the surface they will disperse, resulting in further reduction of the amount of water available to enter through perforations. Numerical modeling of the waste package surface is the next step in extending the concepts developed here. A discrete model of the fracture surface will facilitate the use of arbitrary statistical distributions for perforations, drips which focus the incident flux, and drop impact dispersal processes. Further reductions in bounding values for water entering the waste packages are likely to result.

\section{References}

de Marsily, G., 1986, Quantitative Hydrogeology, Academic Press.

Hildebrand, F. B., 1976, Advanced Calculus for Applications ( $2^{\text {nd }}$ ed.), Prentice-Hall, Englewood Cliffs, NJ.

Strack, O. D. L., 1989, Groundwater Mechanics, Prentice-Hall, Englewood Cliffs, NJ.

*Work performed under the auspices of the U.S. Department of Energy by Lawrence Livermore National Laboratory under Contract W-7405-ENG-48. This work is supported by Yucca Mountain Site Characterization Project, LLNL. 


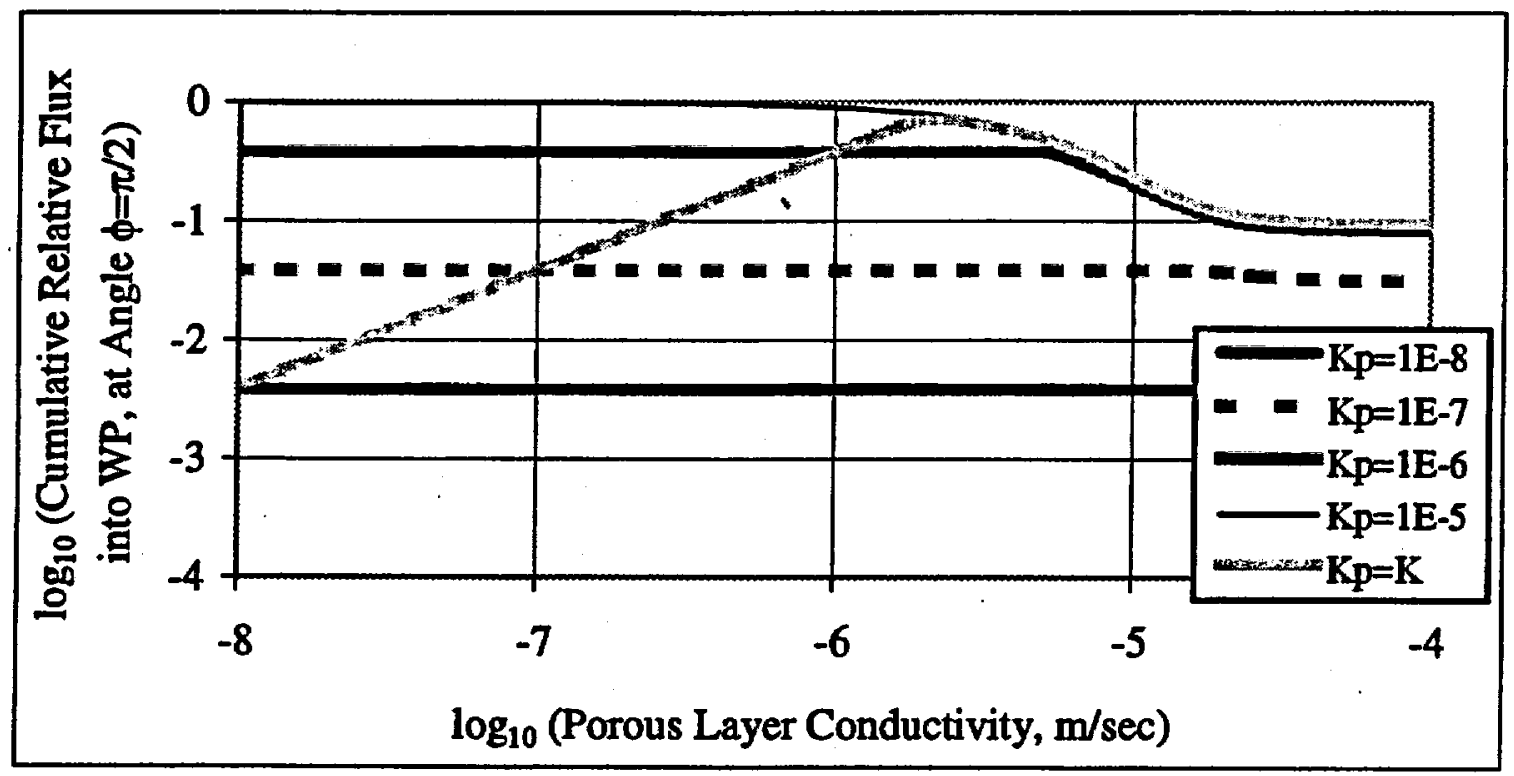

Figure 1. Cumulative flow entering the waste package, calculated form the top to the side. Based on capture analysis for porous layer (Dupuit) flow, taking into account interference between perforations with average number density $100 \mathrm{~m}^{-2}$. At large values of the incident flux, water entering the waste package is limited by perforation plug conductivity. For relatively permeable perforations $\left(K_{p}=10^{-5} \mathrm{~m} / \mathrm{sec}\right)$, much of the incident flux is captured if the porous layer conductivity is small. If the perforation plug conductivity is equal to that of the porous layer $\left(K_{p}=\right.$ $\mathrm{K})$ then less than $10 \%$ of the incident flux enters the waste package. 